\title{
Detección de Cryptosporidium spp. en terneras de lecherías de la Región Metropolitana mediante Ziehl Neelsen y confirmada por inmunocromatografía y ensayo molecular\#
}

\author{
Detection of Cryptosporidium spp. in calves by using a acid fast method and confirmed \\ by immunochromatographic and molecular assays \\ P Muñoz ${ }^{a}$, F Fredes ${ }^{\text {b* }}$, A Díaz-Lee ${ }^{b}$, R Mercado $^{c}$, LS Ozaki $^{d}$ \\ aLaboratorio de Parasitología Veterinaria, Facultad de Ciencias Veterinarias, Universidad Austral de Chile, Valdivia, Chile. \\ bUnidad de Parasitología, Facultad de Ciencias Veterinarias y Pecuarias, Universidad de Chile, Santiago, Chile. \\ ${ }^{c}$ Unidad Docente de Parasitología, Facultad de Medicina, Universidad de Chile, Santiago, Chile. \\ ${ }^{\mathrm{d}}$ Department Microbiology \& Immunology, Medical Center, Virginia Commonwealth University, Virginia, USA.
}

\begin{abstract}
SUMMARY
From an animal production point of view, Cryptosporidium can cause great economic losses in systems that involve the raising of cattle by producing various degrees of diarrhea, particularly in calves that are less than 30 days of age. The main objective of this study was the detection of Cryptosporidium spp. oocysts in faecal samples of diarrheic calves of less than one month of age from two milk farms in the Metropolitan Region of Chile. For the first time in the country, an immunochromatographic and a molecular assay were used to confirm the microscopical observation of Cryptosporidium spp. oocysts in the bovine samples studied. A total of 205 fecal samples were stained with acid-fast method (Ziehl Neelsen, ZN) and 102 (49.8\%) were found to have parasite oocysts. From these $\mathrm{ZN}$ positive samples, 58 were randomly selected and were all confirmed positive by the immunochromatographic test (IC). Conversely, $10 \mathrm{ZN}$ negative samples were all negative by using IC test. A genus-specific molecular assay (18S ribosomal RNA PCR) was designed and carried out in the study of the $58 \mathrm{ZN} / \mathrm{IC}$ positive and the $10 \mathrm{ZN} / \mathrm{IC}$ negative faecal samples for the detection of Cryptosporidium spp. 37 (64\%) samples were confirmed positive by this genus-specific PCR assay while all the $10 \mathrm{ZN/IC} \mathrm{negative} \mathrm{samples} \mathrm{yielded} \mathrm{no} \mathrm{amplification.} \mathrm{Detection}$ limit of the genus-specific PCR was compared with the ZN staining method. Fewer parasites were detected by PCR $\left(10^{4}\right.$ oocysts $\left./ \mathrm{mL}\right)$ when compared to $\mathrm{ZN}\left(2 \times 10^{4}\right.$ oocysts $\left./ \mathrm{mL}\right)$. The results showed that cryptosporidiosis continues to be a parasitic infection of high frequency in dairy farm cattle in the Metropolitan Region. The ZN stain method is extremely operator dependent, but this disadvantage can be reduced by combining ZN with the IC test. Further studies are needed to improve the yield of the genus-specific PCR method as a diagnostic tool for bovine Cryptosporidium. Molecular tests also contribute to define the veterinary epidemiology of this parasitic infection in a specific geographical area.
\end{abstract}

Palabras clave: Cryptosporidium, Ziehl Neelsen, PCR, terneros.

Key words: Cryptosporidium, Ziehl Neelsen, PCR, calves.

\section{INTRODUCCIÓN}

Protozoos del género Cryptosporidium son agentes causales de severos cuadros de diarrea en humanos, rumiantes recién nacidos y otros animales domésticos o silvestres. Esta parasitosis zoonótica se ha descrito en todos los continentes incluido el Antártico (Hunter y col 2003, Fredes y col 2007).

Tyzzer (1907) propuso el nombre del género, enumeró sus principales características morfológicas y describió a Cryptosporidium parvum como la especie involucrada en cuadros diarreicos de roedores (Tyzzer 1912). Actualmente se reconocen 19 especies de Cryptosporidium (Fayer 2010), pero en el caso específico del ganado vacuno la infección es causada principalmente por el patógeno zoonótico C. parvum (Fayer 2004, Sunnotel y col 2006). Sin embargo, también se describen otras especies que producen infección

Aceptado: 27.10.2010.

\# Proyecto DI MULT 06/17-2, Universidad de Chile.

* Casilla 2 Correo 15, La Pintana, Santiago, Chile; ffredes@uchile.cl en esta especie animal tales como: $C$. andersoni, $C$. bovis y $C$. ryanae o $C$. parvum genotipo deer-like (Geurden y col 2006, Feng y col 2007, Fayer 2010). Los dos últimos han sido identificados recientemente en Estados Unidos en ganado bovino (Feng y col 2007).

En el hombre se han descrito al menos ocho especies que provocan infección: C. hominis, C. parvum, C. meleagridis, C. felis, C. canis, C. muris, C. suis y Cryptosporidium genotipo cervine (Cama y col 2008). Los más frecuentes son C. hominis y C. parvum (Xiao y Ryan 2004, Sunnotel y col 2006, Mercado y col 2007, Cama y col 2008); en cambio, $C$. meleagridis ha sido detectada tanto en pacientes inmunocompetentes como inmunodeficientes, pero en una menor tasa (Mercado y col 2007).

En Chile el agente se considera endémico, afectando varias especies animales como equinos, bovinos, ovinos, caprinos, llamas, alpacas, cerdos, perros, gatos, aves (gallinas y palomas) y a humanos (Atías 1998, Alcaíno y Gorman 1999). Hay escasos estudios sobre las especies de Cryptosporidium que estarían infectando a bovinos (C. parvum) y humanos (C. hominis) las que se determinan 
mediante pruebas moleculares (Neira y col 2005, Mercado y col 2007).

La transmisión de este parásito es directa, vía fecal oral por ingesta de alimentos y agua contaminada con ooquistes de donde salen esporozoitos que se desarrollan y multiplican en las células epiteliales del intestino delgado (Tyzzer 1910, Soulsby 1987, Barriga 2002, Fayer 2004). En el caso particular de rumiantes y principalmente en el bovino afecta especialmente a animales menores de 30 días de edad provocando distintos grados de diarrea de tipo no hemorrágica cuando es el único agente presente, así como anorexia, dolor abdominal, pérdida de peso, postración y fiebre con la excreción de un gran número de ooquistes por las heces (Ortega y col 1999, Barriga 2002, Sunnotel y col 2006).

Desde el punto de vista productivo, Cryptosporidium causa pérdidas económicas en sistemas que involucren la crianza de bovinos producto del natural retraso en el crecimiento de los animales y la aplicación de tratamientos con antiparasitarios y antibióticos inespecíficos que no son efectivos contra este agente (Smith y Nichols 2009).

A partir de la descripción realizada por Henricksen y Pohlenz (1981) según la cual los ooquistes de Cryptosporidium poseen la propiedad de ser microorganismos ácido alcohol resistentes, la utilización de exámenes de laboratorio basados en esta propiedad, en especial la tinción modificada de Ziehl Neelsen (ZN), pasaron a ser las pruebas de laboratorio más utilizadas para su diagnóstico (Elliot y col 1999, Fayer y Xiao 2008). Sin embargo, la principal desventaja de este método morfológico-microscópico radica en ser extremadamente operador-dependiente debiendo ser ejecutada por profesionales experimentados (Bowman 2004, Luján y Garbossa 2008).

En Chile, Gorman y col (1989) usando ZN determinaron que un 2,2\% de bovinos sanos y un $23 \%$ de animales diarreicos en la Región Metropolitana eliminaban ooquistes del parásito, y en 1997 se reportó en las regiones VII, IX y X un 30,6\% de prevalencia de infección para Cryptosporidium (Campano 1997).

El propósito del presente estudio fue determinar mediante ZN la frecuencia de hallazgo de Cryptosporidium spp. en terneras diarreicas de dos lecherías de la Región Metropolitana, para contribuir al conocimiento epidemiológico veterinario de esta parasitosis. Complementariamente, por primera vez en Chile se confirmaron los diagnósticos mediante $\mathrm{ZN}$ con una prueba inmunocromatográfica (IC) y una molecular (PCR), determinándose la sensibilidad analítica de $\mathrm{ZN}$ frente al método molecular.

\section{MATERIAL Y MÉTODOS}

Se recolectaron un total de 205 muestras fecales de terneras diarreicas entre 1 y 30 días de edad, de dos lecherías de la Región Metropolitana (Fundo la Macarena, El Monte, 333' S, 7059'O y fundo Pahuilmo, Mallarauco, 3334'S, $71^{\circ} 06^{\prime} \mathrm{O}$ ), durante el año 2008. Las muestras se obtuvieron desde el recto de cada animal y fueron depositadas en tubos plásticos con tapa rosca de $50 \mathrm{ml}$. Las muestras obtenidas fueron depositadas en dos tubos, uno con etanol al $70 \%$ para análisis molecular y otro con formalina al $10 \%$ para el estudio microscópico de ZN. Cada muestra para ZN fue mantenida a $4{ }^{\circ} \mathrm{C}$, en tanto que para el caso de PCR se mantuvo a $-20{ }^{\circ} \mathrm{C}$ hasta ser examinada en el Laboratorio de Parasitología de la Facultad de Ciencias Veterinarias y Pecuarias, Universidad de Chile.

El método ZN se realizó de acuerdo a lo descrito por Henricksen y Pohlenz (1981) y adaptado por Fayer y Xiao (2007).

Para el estudio inmunocromatográfico (IC) se empleó el Kit comercial Crypto-Strip ${ }^{\circledR}$ de laboratorio Coris (Bélgica), siguiendo las instrucciones del fabricante. Esta prueba permite detectar ooquistes de C. parvum en muestras fecales concentradas o no concentradas. La prueba se basa en la utilización de un sistema inmunocromatográfico con partículas de oro coloidal. Es provisto en un kit comercial que se encuentra listo para ser utilizado y sólo requiere una dilución de la muestra fecal en una solución tampón proporcionada por el fabricante, que es puesta en contacto con una tira reactiva (membrana de nitrocelulosa sensibilizada con anticuerpos anti $C$. parvum). La especificidad de la prueba se asegura mediante el empleo de anticuerpos monoclonales dirigidos contra antígenos de superficie de la membrana del ooquiste y conjugado con el oro coloidal.

La extracción de DNA se hizo de acuerdo a lo descrito por Mercado y col (2007), con modificaciones. Las muestras fecales preservadas con etanol, previo tamizaje y centrifugación (1.500 g x 15 minutos), fueron descongeladas a temperatura ambiente. Se utilizaron $300 \mu \mathrm{l}$ de heces a los cuales se le adicionó $300 \mu \mathrm{l}$ de buffer TE (10 mM TRIS-HCl, 1 mM EDTA pH 8,0). Fueron sometidas a ebullición por un minuto, para luego añadirle $300 \mu \mathrm{l}$ de SDS $10 \%$ más $20 \mu \mathrm{l}$ de proteinasa $\mathrm{K} 10 \mathrm{mg} / \mathrm{ml}$. Las muestras se incubaron durante toda la noche a $65^{\circ} \mathrm{C}$ y posteriormente se guardaron a $-20^{\circ} \mathrm{C}$, hasta la extracción de DNA mediante cloroformo-fenol. El DNA fue precipitado con acetato de sodio y posteriormente lavado con etanol 70\%. El pellet obtenido fue disuelto en $50 \mu \mathrm{l}$ de agua estéril para PCR y el volumen utilizado para cada amplificación fue de $3 \mu \mathrm{l}$.

Para la PCR se diseñaron y utilizaron partidores género-específico, que amplifican un segmento de la subunidad $18 \mathrm{~S}$ del gen RNA ribosomal de Cryptosporidium spp. denominados CR18S3543F 5'-GTTAAGTATAAACCCCTTTACAAGTATC-3' y CR18S31078R 5'-CCTCCAATCTCTAGTTGGC-3'. El volumen de DNA utilizado para electroforesis fue de $10 \mu \mathrm{l}$. Se consideró a una PCR positiva por la presencia de una banda de DNA de 522 pb, en un gel de agarosa al 1,5\% en buffer TAE y teñido con bromuro de etidio $(0,5 \mu \mathrm{g} / \mathrm{ml})$.

Las muestras a estudiar fueron amplificadas en un volumen de $25 \mu \mathrm{l}$ con la adición de: $20 \mathrm{ng} / \mu \mathrm{l}$ de cada primer, 
$250 \mu \mathrm{M}$ de cada nucleótido dNTP (dATP, dCTP, dGTP y dTTP), una unidad de DNA Polimerasa (Paq5000M, DNA Polymerase, Stratagene) en buffer $1 \mathrm{X}$ provisto por el fabricante. La amplificación de PCR fue realizada en termociclador Swift Maxi Thermal Cycler ESCO. El DNA fue inicialmente denaturado a $95^{\circ} \mathrm{C}$ por 5 minutos, y luego 30 ciclos de $94{ }^{\circ} \mathrm{C}$ por 30 segundos, $55^{\circ} \mathrm{C}$ por 30 segundos y $72{ }^{\circ} \mathrm{C}$ por 30 segundos. La extensión final fue de $72{ }^{\circ} \mathrm{C}$ por 5 minutos.

El tamaño muestral requerido para detectar la enfermedad mediante el ensayo de PCR se calculó de acuerdo a lo descrito por Thrusfield (2005), que considera que la proporción esperada de positivos cuando la prevalencia en los enfermos es de un 25\% (Gorman y col 1989); y cuando el tamaño de la población es de 200 terneros diarreicos, tabularmente se precisa de una muestra de 11 terneros, para que con una seguridad del $95 \%$ se detecte a lo menos un ternero positivo.

Para determinar la sensibilidad analítica de las pruebas ZN y PCR se realizó un recuento en cámara de Neubauer del número de ooquistes presentes en una muestra PCR positiva, utilizando una rejilla de bronce fosfórico. Luego, a través de diluciones crecientes, se ajustó la concentración de los ooquistes del parásito y finalmente se diluyó nuevamente al doble hasta que éstos no fueron detectados. Cada dilución obtenida fue sometida a tinción mediante ZN y a PCR.

\section{RESULTADOS}

Del total de muestras $(\mathrm{n}=205), 102(49,8 \%)$ resultaron positivas a $\mathrm{ZN}$. De estas muestras, se seleccionaron al azar 58 de las $\mathrm{ZN}$ positivas y 10 de las $\mathrm{ZN}$ negativas. Estas muestras fueron procesadas mediante IC y PCR género-específica. Todas las muestras $\mathrm{ZN}$ positivas también fueron positivas a la prueba IC. De igual manera, las 10 muestras $\mathrm{ZN}$ negativas no dieron reactividad con las tiras de IC. Mediante PCR, 37 (64\%) muestras fecales de terneros diarreicos dieron una banda de amplificación del gen $18 \mathrm{~S}$ rRNA de $522 \mathrm{pb}$ correspondiente a la secuencia blanco del protozoo (figura 1).

Con respecto al límite de detección entre PCR y ZN, la muestra fecal original contenía 365.000 ooquistes $/ \mathrm{ml}$. Para la realización de PCR y ZN se utilizaron $200 \mu \mathrm{l}$ de la muestra, es decir, 73.000 ooquistes. En el cuadro 1 es posible observar el resultado del límite de detección

Cuadro 1. Límite de detección de las pruebas de Ziehl Neelsen y PCR para ooquistes de Cryptosporidium spp. presentes en una muestra de heces de ternera diarreica.

Acid fast stain and PCR detection limit for Cryptosporidium spp. oocyst present in a fecal sample of a diarrheic calf.

\begin{tabular}{lcccc}
\hline & $\begin{array}{c}\text { Ooquistes en muestra } \\
(200 \mu \mathrm{l})\end{array}$ & $\begin{array}{c}\text { Ooquistes por } \\
\text { ml aprox. }\end{array}$ & $\begin{array}{c}\text { Detección } \\
\text { mediante ZN }\end{array}$ & $\begin{array}{c}\text { Detección } \\
\text { mediante PCR }\end{array}$ \\
\hline Sin dilución & 73.000 & 365.000 & Positivo & Positivo \\
$1^{\text {a }}$ dilución & 36.500 & 182.500 & Positivo & Positivo \\
$2^{\text {a }}$ dilución & 18.250 & 91.250 & Positivo & Positivo \\
$3^{\text {a }}$ dilución & 9.125 & 45.625 & Positivo & Positivo \\
$4^{\text {a dilución }}$ & 4.563 & 22.813 & Positivo & Positivo \\
$5^{\text {a dilución }}$ & 2.281 & 11.406 & Negativo & Positivo \\
$6^{\text {a dilución }}$ & 1.141 & 5.703 & Negativo & Negativo \\
$7^{\text {a }}$ dilución & 570 & 2.852 & Negativo & Negativo \\
\hline
\end{tabular}

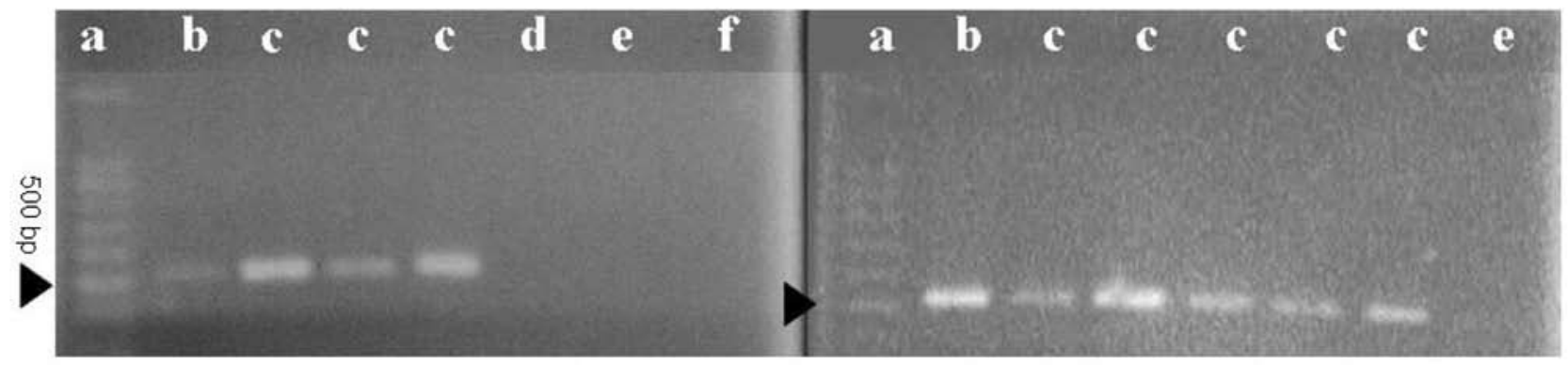

Figura 1. Electroforesis en gel de agarosa de los productos de PCR para la detección del gen 18S rRNA de Cryptosporidium (522 pb) en muestras de heces de terneras diarreicas. a: marcador molecular. b: control positivo. c: muestras positivas a Cryptosporidium spp. d: DNA de Toxoplasma gondii. e: agua de PCR. f: pool de muestras de heces negativas a Cryptosporidium spp.

Agarose gel electrophoresis of PCR products of Cryptosporidium 18S rRNA gene (522 bp) in faecal samples from diarrheic calves. a: molecular marker. b: positive control. c: positive samples for Cryptosporidium spp. d: Toxoplasma gondii DNA. e: PCR water. f: pooled stool samples negative for Cryptosporidium spp. 
mediante PCR y ZN. La máxima dilución detectada por $\mathrm{ZN}$ equivale a $4,6 \times 10^{3}$ ooquistes (22.813 ooquistes $\left./ \mathrm{ml}\right)$, en tanto que mediante PCR, fue posible detectar al parásito en una dilución aun mayor, equivalente a $2,3 \times 10^{3}$ ooquistes (11.406 ooquistes/ml) (figura 2).

\section{DISCUSIÓN}

La cifra de infección por Cryptosporidium spp. de $49,8 \%$ encontrada en los animales que cursaban un cuadro de diarrea fue mayor que las descritas por Gorman y col (1986, 1989) de 23\%, para la Región Metropolitana de Chile. Esto contribuye a la contaminación ambiental de tierras y agua de los predios, con el consecuente riesgo de salud pública que esto pueda significar.

$\mathrm{El}$ control de esta parasitosis en los animales es muy difícil, ya que prevenir la exposición de los terneros a la contaminación es complicado. Las medidas sanitarias y de higiene ayudan a prevenir la presentación de la enfermedad, a disminuir su prevalencia en zonas endémicas y/o a atenuar el riesgo zoonótico (Ortega y col 1999). Sin embargo, la sobrevivencia y diseminación de este parásito es muy probable: primero, ya que los ooquistes son inmediatamente infectantes al salir de su hospedero; segundo, los ooquistes en el ambiente son muy resistentes y pueden permanecer infectivos por dos a tres semanas, incluso pueden sobrevivir en el suelo por más de 50 días a temperaturas inferiores a los $-10{ }^{\circ} \mathrm{C}$ (Kato y col 2002), y tercero, los ooquistes son muy pequeños y resisten a la cloración (Atías 1998, Sturbaum y col 2001, Krewski y col 2004).

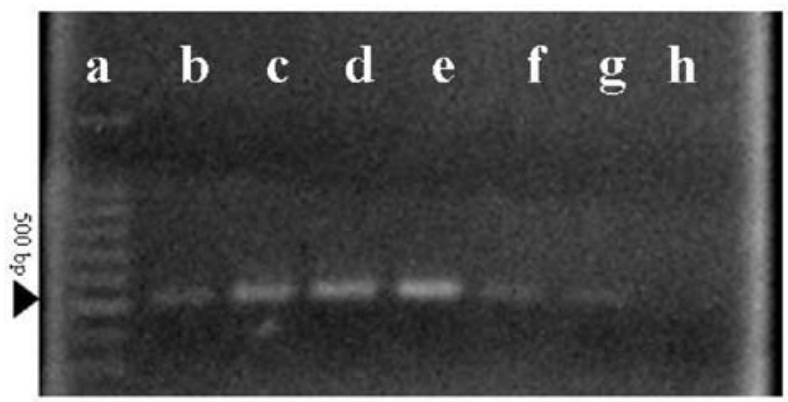

Figura 2. Electroforesis en gel de agarosa de los productos de PCR para la detección del gen 18S rRNA de Cryptosporidium $(522 \mathrm{pb})$ en muestras de heces de terneras diarreicas. a: marcador molecular. b: muestra sin diluir equivalente a 365.000 ooquistes $/ \mathrm{ml}$. c: primera dilución, 182.500 ooquistes $/ \mathrm{ml}$. d: segunda dilución, 91.250 ooquistes $/ \mathrm{ml}$. e: tercera dilución, 45.625 ooquistes $/ \mathrm{ml}$. f: cuarta dilución, 22.813 ooquistes $/ \mathrm{ml}$. g. quinta dilución, 11.406 ooquistes/ml. h: sexta dilución, único carril en que no se observa banda de amplificación.

Agarose gel electrophoresis of PCR products of Cryptosporidium $18 \mathrm{~S}$ rRNA gene (522 bp) in faecal samples from diarrheic calves. a: molecular marker. b: samples without dilute, 365,000 oocysts $/ \mathrm{ml}$. c: first dilution, 182,500 oocysts $/ \mathrm{ml}$. d: second dilution, 91,250 oocysts/ $\mathrm{ml}$. e: third dilution, 45,625 oocysts $/ \mathrm{ml}$. f: fourth dilution, 22.813 oocysts/ $\mathrm{ml}$. g: fifth dilution, 11,406 oocysts $/ \mathrm{ml}$. h: sixth dilution, no amplification band was observed.
Por lo tanto, las altas tasas de infección intrapredial por Cryptosporidium spp. en predios lecheros analizados en esta región pueden deberse a varias causas. Por una parte, ha habido una mayor intensificación de los sistemas productivos, lo que se traduce en un mayor número de animales, hacinamiento de éstos, sumado a posibles deficiencias en las condiciones de higiene e inadecuadas medidas de manejo. Así, por ejemplo, en este estudio, ambos predios muestreados presentaban similares condiciones de higiene y manejo, con terneros estabulados de forma individual, pero con contacto directo entre ellos y separados de la madre al momento de nacer, sin embargo con adecuada administración de calostro. Las medidas de higiene se basaban en la limpieza diaria de los corrales, con extracción del material de cama y las deposiciones, pero sin la aplicación de sustancias desinfectantes. Además, a los animales que presentaban diarrea se les aplicaba tratamiento antibiótico, pero en aquellos en que la diarrea no cedía con éste, no se aplicaba ningún tratamiento o medida adicional, tampoco se hicieron análisis o exámenes de laboratorio, salvo los que finalmente se llevaron a cabo debido a este estudio.

Como está descrito, un punto importante en la prevención y el control de esta parasitosis es la eficiencia en las medidas de manejo de los animales, tanto de tipo alimentario como sanitario (Ortega y col 1999, Duszynski y Upton 2001). Para lograr un óptimo resultado es muy importante contar con el personal adecuado, tanto en la capacitación, como en el compromiso con su trabajo. Este punto fundamental no se cumplía a cabalidad en ninguno de los dos predios muestreados, ya que en ambos el personal a cargo no era estable porque no creaban un verdadero compromiso con la actividad desempeñada.

Las medidas de manejo sugeridas en la literatura para la prevención de la criptosporidiosis son: la destrucción de ooquistes mediante aplicación de desinfectantes eficaces en las zonas que habitan los animales, separación de animales enfermos de sanos, instalar bebederos y comederos altos para evitar la contaminación de éstos con heces. También se aconseja la remoción diaria de materia fecal, controlar la entrada de animales portadores de otras especies (perros, ratones, etc.), mantener las maternidades limpias y desinfectadas, controlar la temperatura y humedad de estos lugares, y procurar que la ingestión de calostro y leche sea la adecuada (Ortega y col 1999, Fayer 2004).

Es necesario recalcar que actualmente la criptosporidiosis se considera tanto en los seres humanos, como en algunos animales, una zoonosis reemergente (Almeida y col 2006, Sunnotel y col 2006); lo anterior debido al gran aumento de factores que pueden llegar a afectar el sistema inmune, provocando inmunodepresión, la cual es una condición preponderante en la presentación humana y animal de esta enfermedad (Fayer y Xiao 2008).

En este estudio se confirmaron los diagnósticos microscópicos $(\mathrm{ZN})$ en muestras positivas y negativas seleccionadas al azar usando una prueba IC diseñada originalmente para 
detectar infecciones por C. parvum en muestras fecales humanas. Esta indica que la especie presente en estos terneros sería $C$. parvum. Sin embargo, para confirmar lo anterior es necesario realizar estudios moleculares que validen estos resultados; o bien enfrentar este test diagnóstico a otras especies de Cryptosporidium descritas en bovinos, previa identificación por biología molecular, en búsqueda de presencia o ausencia de reacciones cruzadas.

Este es el primer reporte de uso de IC dentro del ámbito veterinario en Chile para confirmar infecciones por este protozoo en bovinos. Existe al menos un trabajo extranjero que utilizó un kit IC, pero de diferente proveedor al utilizado en este estudio, con tan buenos resultados como los aquí descritos, encontrándolo rápido, simple y amigable (Trotz-Williams y col 2005).

Por otra parte, se desarrolló y estandarizó por primera vez en Chile, en un laboratorio de diagnóstico veterinario, un PCR género-específico para el diagnóstico de infecciones por Cryptosporidium spp. en muestras de origen animal. Mediante esta prueba molecular fue posible confirmar la existencia de la infección en el 64\% de las 58 muestras $\mathrm{ZN}$ positivas procesadas. Posibles explicaciones para los resultados PCR negativos en el restante $36 \%$ de las muestras fecales serían: a) inadecuada extracción del DNA desde los ooquistes del parásito (Wiedenmann y col 1998, Nikaeen y col 2005); b) degradación del DNA extraído y c) inhibición del PCR. En relación a estas dos últimas, es posible afirmar que el material fecal puede contener DNAsas bacterianas que pueden degradar el material genético liberado. Además, se consideran inhibidores del PCR a las sales biliares, bilirrubina y algunos complejos polisacáridos (Wiedenmann y col 1998, Scorza y col 2003, Jaramillo y col 2008). La concentración de estos inhibidores en las heces es muy variable y depende de muchos factores como la dieta y flora intestinal de los individuos. Otro inhibidor importante es el fitato (myoinositol hexafosfato), sustancia que se encuentra de forma natural en cantidades importantes en el germen y en la cutícula de las semillas vegetales; y que está presente en grandes concentraciones en las heces de los animales herbívoros, actuando como un potente inhibidor del PCR (Thornton y Passen 2004). Los resultados obtenidos muestran que es muy importante frente al uso del PCR, como herramienta diagnóstica de agentes infecciosos en muestras fecales de bovinos, considerar que la inadecuada extracción y degradación del DNA blanco e inhibición afectan la sensibilidad de la prueba.

A pesar de lo anterior, mediante el ensayo de PCR desarrollado, el límite de detección fue superior que al de $\mathrm{ZN}$, ya que se logró detectar aproximadamente $10^{4}$ ooquistes $/ \mathrm{ml}$ de heces, equivalente a $2,3 \times 10^{3}$ ooquistes totales en los $200 \mu \mathrm{l}$ de muestra analizada; versus a los $2 \times 10^{4}$ ooquistes $/ \mathrm{ml}$ de heces detectados, equivalente a $4,6 \times 10^{3}$ ooquistes totales en los $200 \mu \mathrm{l}$ de muestra analizada. Esto demuestra que el PCR es un método más sensible, al ser capaz de detectar una menor cantidad de ooquistes que el método microscópico evaluado.
Por último, se desea enfatizar que las infecciones por Cryptosporidium spp. en terneros diarreicos continúan siendo de elevada frecuencia en la Región Metropolitana del país, lo que probablemente ocasiona un daño de magnitud en estos animales jóvenes de lechería. La observación microscópica de muestras fecales, procesadas mediante ZN en bovinos diarreicos, es útil para diagnosticar la infección en animales. Sin embargo, dada su elevada dependencia con el operador de la prueba, podría ser complementada con el uso de tiras inmunocromatográficas o el empleo de PCR, mejorando en este último la extracción y conservación del DNA del agente.

Lo anterior, a pesar del mayor costo de implementación, permite confirmar los diagnósticos microscópicos así como avanzar en el estudio epidemiológico molecular de las especies del parásito que infectan a los animales y al hombre. Desde el punto de vista de éxito terapéutico, siempre es importante definir y confirmar que agentes infecciosos causan cuadros diarreicos en los distintos hospederos, en particular de aquellos agentes que tienen una dificultad terapéutica como el aquí estudiado.

\section{RESUMEN}

Cryptosporidium causaría gran pérdida económica desde el punto de vista productivo, sobre todo en sistemas que involucren la crianza de bovinos afectando especialmente a animales menores de 30 días de edad con distintos grados de diarrea. El propósito de este estudio fue detectar Cryptosporidium spp. en muestras fecales de terneras diarreicas menores de un mes de edad en dos predios lecheros de la Región Metropolitana. Por primera vez en Chile se usó una prueba inmunocromatográfica (IC) y una molecular (PCR) para confirmar la observación microscópica de los ooquistes de Cryptosporidium spp. en la muestras fecales de bovinos estudiadas. En 49,8\% (102/205) de las muestras fecales se observaron ooquistes de Cryptosporidium spp usando Ziehl Neelsen (ZN). De estas muestras positivas se seleccionaron al azar 58 para confirmar los diagnósticos mediante IC y todas resultaron también positivas. Diez muestras fecales ZN negativas también fueron confirmadas como negativas mediante IC. Mediante PCR en 37 de la $58 \mathrm{ZN}$ positivas (64\%) se obtuvo un resultado positivo. La PCR también fue realizada en las diez muestras IC negativas sin obtener amplificación. La técnica molecular fue capaz de detectar muestras con menos ooquistes $\left(10^{4}\right.$ ooquistes $\left./ \mathrm{ml}\right)$ en comparación con $\mathrm{ZN}$ ( $2 \times 10^{4}$ ooquistes $\left./ \mathrm{ml}\right)$. Los resultados obtenidos permiten afirmar que la criptosporidiosis bovina sigue siendo una infección parasitaria de alta frecuencia en predios lecheros en la Región Metropolitana. Desde el punto de vista diagnóstico, la combinación de ZN con IC permitiría reducir la desventaja de $\mathrm{ZN}$ de ser una prueba operador dependiente. Se requiere de nuevos estudios que busquen incrementar el rendimiento de la PCR como prueba diagnóstica en la criptosporidiosis bovina. La implementación de pruebas moleculares también contribuye al estudio epidemiológico veterinario de esta parasitosis en una determinada área geográfica.

\section{AGRADECIMIENTOS}

Los autores desean agradecer al Dr. Leonardo Sáenz, Centro Biotecnológico Veterinario de la Facultad de Cs. Veterinarias y Pecuarias, Universidad de Chile, por su apoyo y orientación en la estandarización de la prueba molecular. Además, se agradece a los propietarios y al personal de las lecherías en cuestión por su colaboración, incluidos los Dres. Luis Moraga y Mario Duchens. 


\section{REFERENCIAS}

Alcaíno H, T Gorman. 1999. Parásitos de los animales domésticos en Chile. Parasitol al día 23, 33-41.

Almeida A, M Delgado, S Soares, A Castro, M Moreira, C Mendonca, N Canada, J Correira Da Costa, H Coelho. 2006. Genetic characterization of Cryptosporidium isolates from humans in Northern Portugal. J Eukaryot Microbiol 53, 26-27.

Atías A. 1998. Criptosporidiosis. En: Atías A (ed). Parasitología Médica. Ed. Mediterráneo, Santiago, Chile, Pp 146-151.

Barriga O. 2002. Las Criptosporidiasis. En: Barriga O (ed). Las enfermedades parasitarias de los animales domésticos en la América Latina. Ed. Germinal, Santiago, Chile, Pp 187-188.

Bowman D. 2004. Protozoos. En: Bowman D (ed). Goergis Parasitología para Veterinarios. 8 $^{\mathrm{a}}$ ed. Saunders, Madrid, España, Pp 103-105.

Cama VA, C Bern, J Roberts, L Cabrera, CR Sterling, Y Ortega, RH Gilman, L Xiao. 2008. Cryptosporidium species and subtypes and clinical manifestations in children, Perú. Emerg Infec Dis 14, $1567-1574$

Campano S. 1997. La criptosporidiosis de los animales domésticos. Bol Epizootiol 6, 25-35.

Duszynski D, S Upton. 2001. Cyclospora, Eimeria, Isospora and Cryptosporidium spp. In: William S (ed). Parasitic Diseases of Wild Mammals. $2^{\text {nd }}$ ed. Iowa States University Press, Iowa, USA, Pp 430-442.

Elliot A, UM Morgan, RCA Thompson. 1999. Improved staining method for detecting Cryptosporidium oocysts in stools using malachite green. J Gen Appl Microbiol 45, 139-142.

Fayer R. 2004. Cryptosporidium: a water-borne zoonotic parasite. Vet Parasitol 126, 37-56.

Fayer R, L Xiao. 2008. Diagnostics of Cryptosporidium. In: Fayer R (ed). Cryptosporidium and Cryptosporidiosis. $2^{\text {nd }}$ ed. CRC Press, Florida, USA, Pp 173-202

Fayer R. 2010. Taxonomy and species delimitation in Cryptosporidium. Exp Parasitol 124, 90-97.

Feng Y, Y Ortega, G He, P Das, M Xu, X Zhang, R Fayer, W Gatei, V Cama, L Xiao. 2007. Wide geographic distribution of Cryptosporidium bovis and the deer-like genotype in bovines. Vet Parasitol 144, 1-9.

Fredes F, E Raffo, P Muñoz. 2007. First report of Cryptosporidium spp. oocysts in stool of Adelie penguin from the Antarctic using acid-fast stain. Antarct Sci 19, 437-438.

Geurden T, FY Goma, J Siwila, IGK Phiri, AM Mwanza, S Gabriel, E Claerebout, J Vercruysse. 2006. Prevalence and genotyping of Cryptosporidium in three cattle husbandry systems in Zambia. Vet Parasitol 138, 217-222.

Gorman T, H Alcaíno, J Santelices. 1989. Cryptosporidium y otras coccidias intestinales en terneros de lechería. Región Metropolitana. Chile. Arch Med Vet 21, 29-34.

Gorman T, H Alcaíno, J Weitz. 1986. Hallazgo de Cryptosporidium en animales de Chile. Parasitol al día 10, 31-32.

Henricksen SA, JFL Pohlenz. 1981. Staining of cryptosporidia by modified Ziehl-Neelsen technique. Acta Vet Scand 22, 594-596.

Hunter P, R Chalmers, Q Syed, S Hughes, S Woodhouse, L Swift. 2003. Foot and mouth disease and Cryptosporidiosis: possible interaction between two emerging infectious diseases. Emerg Infect Dis 9, 109-111.

Jaramillo H, R Patiño, J Rodríguez. 2008. Detección molecular por PCR de Yersinia pseudotuberculosis en materia fecal de cuyes (Cavia porcellus). Rev Corpoica 9, 62-71.
Kato S, M Jenkins, E Fogarty, D Bowman. 2002. Effects of freeze-thaw events on the viability of Cryptosporidium parvum oocysts in soil. $J$ Parasitol 88, 718-722.

Krewski D, J Balbus, D Butler-Jones, CN Haas, J Isaac-Renton, KJ Roberts, M Sinclair. 2004. Managing the microbiological risks of drinking water. J Tox Env Health Part A 67,1591-1617.

Luján N, G Garbossa. 2008. Cryptosporidium: 100 años después. Acta Bioquim Clin Latinoam 42, 195-201.

Mercado R, G Buck, P Manque, L Ozaki. 2007. Cryptosporidium hominis infection on the human respiratory tract. Emerg Infect Dis $13,462-464$.

Neira-Otero P, N Muñoz-Saldías, M Sánchez-Moreno, MJ RosalesLombardo. 2005. Molecular characterization of Cryptosporidium species and genotypes in Chile. Parasitol Res 97, 63-67.

Nikaeen M, A Mesdaghinia, M Jeddi Tehrani, M Rezaeian, K Makimura. 2005. A Nested-PCR assay for detection of Cryptosporidium parvum oocysts in water samples. Iranian J Publ Health 34, 13-18.

Ortega LM, M Gómez, FA Rojo. 1999. Criptosporidiosis. En: Cordero del Campillo M (ed). Parasitología Veterinaria. Ed. McGraw-Hill, Interamericana, Madrid, España, Pp 213-221.

Scorza AV, MM Brewer, MR Lappin. 2003. Polymerase chain reaction for the detection of Cryptosporidium spp. in cat feces. J Parasitol $89,423-426$.

Smith HV, RAB Nichols. 2009. Cryptosporidium: detection in water and food. Exp Parasitol 124, 61-79.

Soulsby E. 1987. Phylum Apicomplexa Levine, 1970. En: Soulsby E (ed). Parasitología y enfermedades parasitarias en los animales domésticos. $7^{\mathrm{a}}$ ed. Nueva Editorial Interamericana, México DF, México, Pp 601-639.

Sturbaum G, C Reed, P Hoover, H Jost, M Marshall, C Sterling. 2001. Species-specific, nested PCR-restriction fragment length polymorphism detection of single Cryptosporidium parvum oocysts. Appl Environ Microb 67, 2665-2668.

Sunnotel O, X Snelling, K Moule, JE Moore, BC Millar, JSG Dooley, CJ Lowery. 2006. Rapid and sensitive detection of single Cryptosporidium oocysts from archived glass slides. J Clin Microbiol 44, 3285-3291.

Thornton CG, S Passen. 2004. Inhibition of PCR amplification by phytic acid, and treatment of bovine fecal specimens with phytase to reduce inhibition. J Microbiol Meth 59, 43-52.

Thrusfield M. 2005. Surveys. In: Thrusfield M (ed). Veterinary Epidemiology. $3^{\text {rd }}$ ed. Blackwell Publishing, Edinburgh, UK, Pp 232-242.

Trotz-Williams LA, SW Martin, D Martin, T Duffield, KE Leslie, DV Nydam, F Jamieson, AS Peregrine. 2005. Multiattribute evaluation of two simple tests for the detection of Cryptosporidium parvum in calf faeces. Vet Parasitol 134, 15-23.

Tyzzer EE. 1907. A sporozoan found in the peptic glands of the common mouse. Proc Soc Exp Biol 5, 12-13.

Tyzzer EE. 1910. An extracellular coccidium, Cryptosporidium muris (gen. et sp. nov.), of the gastric glands of the common mouse. J Med Res 23, 487-511.

Tyzzer EE. 1912. Cryptospordium parvum (sp. nov.), a coccidium found in the small intestine of the common mouse. Archiv fur Protistenkunde 26, 394-412.

Wiedenmann A, P Kruger, K Botzenhart. 1998. PCR detection of Cryptosporidium parvum in environmental samples-a review of published protocols and current developments. $J$ Ind Microbiol Biot 21, 150-166.

Xiao L, UM Ryan. 2004. Cryptosporidiosis: an update in molecular epidemiology. Curr Op Infec Dis 17, 483-490. 